\title{
Viscoelastic Polyurethane Foams From Unmodified Kraft Lignin Dispersed Into Methoxy Polyethylene Glycol and Palm Kernel Oil as Substitutes of Petroleum-Based Polyols
}

\section{Camila Campos Flôres}

Federal University of Sao Paulo: Universidade Federal de Sao Paulo

Thiago do C. Rufino C Rufino

The Dow Chemical Company

\section{Lara Robert Nahra}

Federal University of Sao Paulo: Universidade Federal de Sao Paulo Isabelle Christine Zavecz Rodrigues

Federal University of Sao Paulo: Universidade Federal de Sao Paulo Mauricio Pinheiro Oliveira ( $\square$ mauricio.pinheiro@unifesp.br)

Federal University of Sao Paulo: Universidade Federal de Sao Paulo https://orcid.org/0000-0002-82105134

\section{Research Article}

Keywords: Kraft lignin. Dispersion, polyurethane foam, viscoelastic PU foam, palm kernel oil, polyethylene glycol

Posted Date: February 2nd, 2022

DOI: https://doi.org/10.21203/rs.3.rs-1143211/v1

License: (9) This work is licensed under a Creative Commons Attribution 4.0 International License. Read Full License 


\section{Abstract}

Kraft lignin (KL) dispersions in methoxy polyethylene glycol (MPEG) and in a mixture of palm kernel oil (PKO) with MPEG (PKO/MPEG) were evaluated for viscoelastic polyurethane foams (VPFs) production with different contents of KL (0-3.9 pphp) and PKO (0 -15 pphp). The influence of the dispersed KL on the foam structure, foam growth profile, foaming reactivity, mechanical properties, and final properties of VPFs were studied. The appearance of the VPF produced with KL dispersion in MPEG/PKO was similar to the control VPF foam. The addition of KL dispersion ( 0 to $15 \mathrm{pphp}$ ), had a significant effect on the growth profile, foaming reactivity, density and consequently on the foam morphology. VPFs produced with 3.9 pphp of KL presented shrinkage values about 4 times when compared to the control. The presence of the $\mathrm{KL}$ and PKO did not improve the burning rate of the foam samples compared to the control foam, without $\mathrm{KL}$ and PKO. Thermal stability of the produced foams showed no relevant differences regardless of the contents of KL/MPEG/PKO used in comparison to the control. Mechanical properties of VPF can be adjusted by making changes to the standard formulation. It can be concluded that the dispersion of $K L$ in a mixture of MPEG and PKO represents an alternative for incorporating fractions of KL and PKO into VPF. In addition, this study provides new insights for the production of VPF using renewable resources for packaging applications, as well as in the mattress industry.

\section{Introduction}

Kraft lignin $(\mathrm{KL})$ is considered a promising product from renewable resources and has attracted lots of attention in recent years due to specific application properties, substitution of petroleum-based raw materials for ecological and economic balance [1-3]. KL is an amorphous macromolecule and presents a very complex structure, which differs substantially from native lignin in monomer composition, molar mass distribution, solubility in water and in several organic solvents $[5,6]$. Usually, $\mathrm{KL}$ can be obtained in large quantities from the black liquor of the paper industry via acidification/precipitation methods, such as the LignoBoost process, WestVasco process and the LignoForce System TM [6,7]. Normally, carbon dioxide and sulphuric acid are used, followed by hot filtration. According to Kienberger et al. [7] and Garlapati et al. [8], the annual global production of KL in the paper and cellulose separation processes is $\sim 60$ million tons, and approximately $1-2 \%$ are used for the production of added-value products. Large part of this $\mathrm{KL}(\approx 98 \%)$ is treated as waste material and burned for energy recovery in the paper and cellulose industry [7-9]. Many efforts have been made to transform low value $\mathrm{KL}$ to high-value products such as polyurethane foams, as a strategy to replace petroleum-based polyols [10-18]. However, there are several opportunities associated with the use, dispersion and incorporation of $\mathrm{KL}$, as partial substitutes of petroleum-based polyols for VPF.

Given the industrial and scientific importance of $\mathrm{KL}$ to produce new materials from renewable sources, several challenges have been identified for the replacement of petroleum-based polyols with $\mathrm{KL}$ that have limited its utility in PU foams. KL obtained from the black liquor offers both aliphatic and aromatic hydroxyl group which, in turn, are suitable to further react with isocyanates to produce polyurethanes $[19,20]$. The main challenges in the lignin-incorporated PU foams are attributed to the 
heterogeneous and complex chemical structure, reactivity of hydroxyl groups, poor incorporation into polymer matrix, high molar mass dispersity, poor solubility and dispersion in polyols, that are commonly used for the synthesis of PU foams $[10,19,20]$. Usually, KL tends to agglomerate and forms heterogeneous mixtures of micro and nanoparticles in common polyols [19-21]. The direct use of KL (up to $64 \mathrm{wt} \%$ ) under mixing in the petroleum-based polyols has resulted in PU foams with inferior mechanical properties compared to PU foams based solely on petroleum-based polyols $[19,20]$. Hayati et al. [19] reported a significant improvement in the dispersion of $\mathrm{KL}(5 \mathrm{wt} \%)$ in a polyether polyol mixture with $4 \mathrm{wt} \%$ glycerol at $120^{\circ} \mathrm{C}$ and in the compressive strength of the PU foams. Haridevan et al. [20] and $\mathrm{Li}$ et al. [22] reported the use of lignin solubilized in polyethylene glycol (PEG, $400 \mathrm{~g} / \mathrm{mol}$ ) and glycerol to prepare PU foams. Ahvazi et al. [23] reported enhanced dispersion of lignin in aromatic polyester polyol with formation of ligno-polyols through both physical and chemical linkages.

Vegetable oils, such as palm kernel oil (PKO) can be used as chain extender and substitutes of petroleumbased polyols for bio-based PU foams [18,22,24]. Considering that the homogeneity and stability of KL dispersion is affected by the incorporation approach, lignin structures, the loading levels and polyol structures [20], PKO would be a better choice as a compatibilizer and dispersing agent between the MPEG and $\mathrm{KL}$ given it is a low molar mass. However, there are no reports of the combination of MPEG and PKO as dispersing agent for KL. PKO is obtained from the kernel part of the oil palm fruit, which consists of lauric, oleic and myristic acids, and has also been used in the synthesis of bio-polyols to replace petroleum-based polyols [18,22-27]. For example, Lat et al. [18] reported the use of PKO to produce PUbased PKO with flexible characteristics. Pawlik and Prociak [25] reported the use the bio-polyol based on palm oil on PU foam properties. According to the authors [25], flexile PU foams were obtained by substituting a part of petroleum polyether-polyol with the bio-polyol based on palm oil. However, there are several opportunities to further develop such PU technology towards sustainability. This study looks at an alternative strategy for increasing the dispersion of industrial KL in MPEG with $550 \mathrm{~g} / \mathrm{mol}$ and in a MPEG/PKO mixtures for VPF production as substitutes of petroleum-based polyols and investigates its influence on the properties of VPF.

Viscoelastic polyurethane foams (VPFs) are widely in several industrial applications, such as airplane seats, headphones, packaging, helmet liners, gym mats, ear plugs, pillows, and toppers for mattresses [27,28], due to their response to a stress stimulus being a strain with enough delay to be remarkably pronounced at macroscopic level. Despite the long response delay (viscous effect), VPF are able to recover their original dimensions (elastic effect) once the stress on the foam is ceased. The behavior of VPF is a result of the underlying polymer structure and is controlled by the formulation that the foam designer uses. Despite of the evident relevance of VPF to the daily basis, there are few reports on VPF using bio-based raw materials as a strategy to reduce the environmental impact of this class of materials [18,22-28]. The present work combined the features from KL and PKO into VPFs as a sustainability strategy to replace part of MPEG, while adding economic feasibility. Hopefully, combining PKO and MPEG would be suitable to produce KL dispersions with superior kinetic stability and KL 
content, while keeping the viscoelastic properties of the resulting PU foams. Besides, this study provides new insights to production of KL-VPFs for industrial application.

Therefore, this study aims to improve the dispersion of $\mathrm{KL}$ directly in a commercial polyol (MPEG 550) and in a mixture of MPEG/PKO for VPF production. KL dispersions in MPEG and in a mixture with PKO were evaluated using different contents of KL, MPEG and PKO, different dispersion temperature and time. The influence of the dispersed $K L$ on the foam structure, foam growth profile, foaming reactivity, flame retardance and mechanical properties were studied. The present work is a continuation of our earlier studies in collaboration with The Dow Chemical Company (Brazil) on the establishment of cost-effective strategy for the use of industrial KL as partial substitutes of petroleum-based polyols for VE-PU foams.

\section{Experimental}

\subsection{Materials}

Kraft lignin $(\mathrm{KL})$ was supplied by Suzano Celulose S.A. from its pilot-plant (LignoBoost process) with a $\mathrm{pH}$ of 8.6 , total hydroxyl number $(\mathrm{nOH})$ of $185 \mathrm{mgKOH} / \mathrm{g}$, weight-average molar mass $\left(M_{w}\right)$ of 6820 $\mathrm{g} / \mathrm{mol}$, number-average molar mass $\left(M_{n}\right)$ of $2930 \mathrm{~g} / \mathrm{mol}$ and dispersity $(~(D=M w / M n)$ of 2.33. KL was also found to have $2.0 \%$ of sulfur, $0.3 \%$ of nitrogen and glass transition temperature $(\mathrm{Tg})$ of $133^{\circ} \mathrm{C}$. Details of the KL characterization have been reported previously by Flores et al. [28]. Palm kernel oil (PKO) with $43.8 \%$ of lauric acid, $17.7 \%$ of oleic acid, acid number of $0.95 \mathrm{mgKOH} / \mathrm{g}$, viscosity of 48 $\mathrm{mPa} . \mathrm{s}$, hydroxyl number of $1.6 \mathrm{mg} \mathrm{KOH} / \mathrm{g}$ and molar mass $\left(M_{W}\right)$ of $715 \mathrm{~g} / \mathrm{mol}$ was supplied by Triângulo Alimentos Ltda (Brazil), and was used as received (Table S2 and S3 in the Supplementary Information). Polyols (propylene-oxide-polyether triol, PEO/PO (Voranol' ${ }^{\text {T' }}$ CP 1421), propylene-glycolpolyether diol, PPG (Voranol ${ }^{\text {Tm }}$ 2120) and methoxy-poly(ethylene glycol) - Carbowax ${ }^{\text {Tm }}$ MPEG 550 were supplied by Dow Chem. (Brazil). The properties of both petroleum-based polyols are summarized in Table S1 (Supplementary Information). Vorasurf ${ }^{\mathrm{m}} 504$ from Dow Chem. (Brazil) and Tegostab ${ }^{\circledR}$ B 8228 from Evonik Brazil Ltda were utilized as the surfactants to control the foam and cell morphology. The catalysts for the synthesis of VE-PU foams were composed of bis (2-dimethylaminoethyl) ether (DABCO ${ }^{\circledR} B L 11$, Evonik Brazil Ltda) and triethylenediamine $\left(\mathrm{DABCO}^{\circledR} 33-\mathrm{LV}\right.$, Evonik Brazil Ltda), both solubilized in dipropylene glycol. Methylenediphenyl diisocyanate pre-polymer (Specflex ${ }^{\mathrm{TM}} \mathrm{NE} 134$ ) with $30 \%$ NCO groups and viscosity of $98 \mathrm{mPa}$.s was supplied by Dow Chem. (Brazil). Deionized water (DW) was used throughout the study.

\subsection{Preparation of KL dispersion (KLD)}

The effect of KL dispersion in MPEG and MPEG/PKO at different loading levels on the viscosity and stability of $K L$ dispersion were investigated. The polyol (Carbowax ${ }^{T M}$ MPEG 550) was selected to prepare $\mathrm{KL}$ dispersion (KLD) by increasing the $\mathrm{KL}$ contents. MPEG/KL and MPEG/KL/PKO dispersions were prepared according to the literature $[19,20,29]$, with slight modifications. Different strategies of KL dispersion were used (KL content, dispersion temperature and time) aiming to elaborate VPFs based on 
the bio-based materials. $\mathrm{KL}$ powder was dried in an oven at $100^{\circ} \mathrm{C}$ for $2 \mathrm{~h}$, dispersed in a $2000-\mathrm{mL}$ threeneck round-bottom flask in $1000 \mathrm{~g}$ of MPEG 550 under mechanical stirring (Cowles impeller) at $150 \mathrm{rpm}$ for 2.5 to $4.5 \mathrm{~h}$ at $(55-90 \pm 2){ }^{\circ} \mathrm{C}$ (Table 55 in the Supplementary Information). In the KL/MPEG/PKO dispersion series the amount of $\mathrm{KL}(30 \mathrm{w} \%)$ was kept constant and the dispersions were prepared with PKO and MPEG loading from 0 to $50 \mathrm{wt} \%$ and 20 to $70 \mathrm{wt} \%$, respectively. Afterward, the dispersions were filtered through a stainless-steel mesh of $125 \mu \mathrm{m}$ and the dispersibility was evaluated gravimetrically at $180^{\circ} \mathrm{C}$. The weight fraction of $\mathrm{KL}$ soluble/dispersed in MPEG was determined from the initial $\mathrm{KL}$ weight. The dispersions were conditioned at $(25 \pm 2){ }^{\circ} \mathrm{C}$ for 7 and any insoluble or aggregated materials were separated by filtration using a stainless-steel mesh of $125 \mu \mathrm{m}$ and the stability was determined gravimetrically. The viscosity of the polyols, PKO and KL dispersions was determined using a Brookfield DV II+ viscosimeter at $(40 \pm 1){ }^{\circ} \mathrm{C}$, using a spindlen ${ }^{\circ} 21$ and a shearing speed of $50 \mathrm{~s}^{-1}$. KL dispersion was evaluated using optical microscopy (FEI Philips, INSPECT-S50) and a Zehntner- Grindometer ZGR 2020 (Fig. S4 in the Supplementary Information). Hydroxyl number (nOH) of PKO, KL and polyols were determined by titration with $1.0 \mathrm{~mol} / \mathrm{L} \mathrm{KOH}$ standard solution, according to ASTM 2849-69 [30] through acetylation and acid base volumetric titration (Table S1 and S4 in the Supplementary Information).

\subsection{VPF foam synthesis}

VPFs were synthesized by using the bench mixer with different ratios of KL dispersion, PKO and petroleum-based polyols. Initially, polyether PEO/PO triol (57.5 to 78.0 parts per hundred part of polyol pphp), PPG diol (12.5 to 15.0 pphp), MPEG (3.7 to 15 pphp), KLD (1.3 to $3.9 \mathrm{pphp}$ of KL), PKO (5.0 to 15.0 pphp), surfactant Vorasurf 504 (2.4 g), surfactant Tegostab ${ }^{\circledR}$ B 8228 (0.9 g), DABCO ${ }^{\circledR}$ BL11 (0.1 g), $\mathrm{DABCO}{ }^{\circledR} 33 \mathrm{LV}(0.5 \mathrm{~g})$ and deionized water $(3.4 \mathrm{~g})$ as blowing agent, were mixed for 1 min using a hightorque mixer at $3000 \mathrm{rpm}$ and $25^{\circ} \mathrm{C}$ to obtain a uniform mixture. Finally, methylenediphenyl diisocyanate pre-polymer (Specflex "' NE 134) was added into the mixture and remained under agitation for $7 \mathrm{~s}$. Immediately after, the mixture was poured into a cardboard mold of $25 \mathrm{~cm}^{2}$ for the growth of the foam and then was cured at $(25 \pm 2){ }^{\circ} \mathrm{C}$ for $168 \mathrm{~h}$ before further characterization. The foams without $\mathrm{KL} / \mathrm{PKO}$ mixture were prepared following the same procedure as described above. The isocyanate index used in this study was 1.15 and was calculated according to the desired molar ratio of isocyanate and hydroxyl groups. Table 2 shows experimental design conditions used for the synthesis of VPFs.

Table 1 Experimental conditions used for the synthesis of VPFs with different contents of KL/MPEG/PKO. 


\section{Components (pphp) VPF Formulations}

\begin{tabular}{lccccccc} 
& \multicolumn{1}{c}{$\boldsymbol{P 1}$} & $\boldsymbol{P 2}$ & $\boldsymbol{P 3}$ & $\boldsymbol{P 4}$ & $\boldsymbol{P 5}$ & $\boldsymbol{P 6}$ & $\boldsymbol{P 7}$ \\
\hline PEO/PO triol & 70.0 & 70.0 & 66.0 & 66.0 & 66.0 & 57.5 & 70.0 \\
\hline PPG diol & 15.0 & 15.0 & 14.0 & 14.0 & 14.0 & 12.5 & 15.0 \\
\hline \multicolumn{2}{c}{ KL dispersion } & & & & & \\
\hline MPEG 550 & 15.0 & 5.6 & 7.4 & 11.1 & 3.7 & 11.1 & - \\
\hline KL & - & 1.9 & 2.6 & 3.9 & 1.3 & 3.9 & - \\
\hline PKO & - & 7.5 & 10.0 & 5.0 & 15.0 & 15.0 & 15.0
\end{tabular}

\subsection{VE Foam characterization}

\subsubsection{Foam rise profile}

The foam growth profile and reactivity of VPF formulations were evaluated through the gel time (string time), average speed of growth, shrinkage and tack-free time. The Foamat ${ }^{\circledR} 285$ equipment (Format Messtechnik $\mathrm{GmbH}$ ) was used to gather several foam parameters, including foam height, core temperature, inner pressure and mixture capacitance. It consists of a cylindrical reservoir equipped with a thermocouple and a pressure transducer. Moreover, these parameters were tracked over time and the results are expressed as a time profile for each evaluated parameter.

\subsubsection{Density}

The apparent density of foam samples was determined from the mass-to-volume ratio of foam samples. The samples were dried at $40^{\circ} \mathrm{C}$ for $4 \mathrm{~h}$ and the analysis was carried out according to Brazilian Association of Technical Standard test method (ABNT NBR 8537-03) [31]. Specimen shape, length, width, and thickness, $(10 \times 10 \times 5) \mathrm{cm}^{3}$, were prepared according to ABNT NBR 9429-2003 [32].

\subsubsection{Morphology}

The morphology and uniformity of VPF samples were observed by scanning electron microscopy (SEM, FEl, Inspect S50) at $15 \mathrm{kV}$. Each samples was cut to, length, width, and thickness, $(5 \times 5 \times 5) \mathrm{mm}^{3}$, and was attached to a substrate with an adhesive tape and then coated with a thin gold layer by sputtering. The average cell size of the VPF was determined from the SEM images using the image analysis (ImageJ) software. In order to represent the average diameters, different cells on the SEM micrographs were measured and the average values were presented.

\subsubsection{Recovery time measurement}

The viscoelastic and recovery testing of VPFs were conducted using a Resimat ${ }^{\circledR} 150$ (Format Messtechnik $\mathrm{GmbH})$. The samples of standard dimensions, length, width, and thickness, $(10 \times 10 \times 5) \mathrm{cm}^{3}$, were 
compressed vertically be means of a pressure plate to $50 \%$ of the sample's initial thickness. During the test, the force necessary to maintain the deformation was measured. After a pre-determined interval, the sample was uncompressed and left free to gradually recover from the $50 \%$ deformation $[28,33]$. The force and recovery time were measured and reported according to the IOS-MAT-0076.

\subsubsection{Compression set test (Cset)}

The compression set test measures the permanent set of the foam after specified conditions of time and temperature. Compression set test of VPFs was measured using a universal testing machine according to the standard ABNT NBR-8797-03 [35]. Samples were cut down to $100 \times 100 \times 50 \mathrm{~mm}$ blocks. Specimens were stored at $(24 \pm 1){ }^{\circ} \mathrm{C}$ and $(50 \pm 5) \% \mathrm{RH}$ and were subsequently compressed to (50 \pm 1$) \%$ of their original thickness. The original thickness measurements $\left(\mathrm{i}_{0}\right)$ were performed and the Cset values were determined after $22 \mathrm{~h}$ at $(70 \pm 2)^{\circ} \mathrm{C}$. The temperature was kept constant during the test and, after, the samples were cooled down to $(25 \pm 1){ }^{\circ} \mathrm{C}$. Finally, the final thickness of samples $\left(\mathrm{i}_{1}\right)$ was measured and $50 \%$ Cset values of PU foams were calculated according to Eq., where $i_{0}$ and $i_{1}$ are the original and final thickness of the test specimen, respectively.

$$
C_{\text {set }}(\%)=\left(\frac{i_{0}-i_{1}}{i_{0}}\right) \times 100
$$

\subsubsection{Resilience}

The resilience of VPF samples was investigated by the ball rebound test method according to the standard ABNT NBR-8619-03 [36]. For this, a graduated tube was positioned vertically over the center of the specimens, length, width, and thickness $(10 \times 10 \times 5) \mathrm{cm}^{3}$, and a steel ball of $(16.0 \pm 0.1) \mathrm{mm}$ diameter was released from the fixed height $(0.5 \mathrm{~m})$ and the rebound height was determined.

\subsubsection{Tear strenght}

Tear strength measures the VPF samples resistance to tearing and it is related to the durability of the foam. Tear strenght of VPF samples were conducted in duplicate on dynamometer (Instron model 1185), according to the standard NBR 8516 [37]. Samples of, length $(200 \mathrm{~mm})$ and width $(75 \mathrm{~mm})$ were stored at $(24 \pm 1)^{\circ} \mathrm{C}$ and $(50 \pm 5) \% \mathrm{RH}$ and were subsequently attached by the ends to the claws of the equipment. The tension was applied evenly distributed in the cross section and the force per unit length (the thickness of the specimen) was measured.

\subsubsection{Dynamic mechanical thermal analysis (DMTA))}

Dynamic mechanical analysisof VPFs was carried out with a DMTA dynamic mechanical thermal analyzer (TA Instruments RSA-G2). The dimensions of specimens were $20 \mathrm{~mm} \times 20 \mathrm{~mm} \times 20 \mathrm{~mm}$ (width $\times$ length $\times$ thickness). Specimens were analyzed in compression mode between two parallel plates with 
diameter of $25 \mathrm{~mm}$. Measurements were recorded at the frequency of $1 \mathrm{~Hz}$ in the range of temperatures from -50 to $200{ }^{\circ} \mathrm{C}$ at a heating rate of $3{ }^{\circ} \mathrm{C} / \mathrm{min}$, under nitrogen atmosphere at a flow rate of $50 \mathrm{~mL} / \mathrm{min}$.

\subsubsection{Thermogravimetric analysis (TGA)}

Thermal stability of VPF was determined by thermogravimetric analysis (TGA, Netzsch 204 F1) at a heating rate of $20^{\circ} \mathrm{C} / \mathrm{min}$. The samples were drying in a vacuum oven at $(40 \pm 2){ }^{\circ} \mathrm{C}$ for $4 \mathrm{~h}$ and approximately $8-10 \mathrm{mg}$ of each sample were heated from 30 to $800{ }^{\circ} \mathrm{C}$ in a nitrogen atmosphere at a flow rate of $90 \mathrm{~mL} / \mathrm{min}$.

\subsubsection{Flammability Testing}

The horizontal burning tests were conducted according UL-94 [34] and ISO 5660. The specimens $(125 \times 13 \times 10) \mathrm{mm}$ were conditioned to $(23 \pm 2)^{\circ} \mathrm{C}$ and $\mathrm{RH}(50 \pm 5) \%$ for $48 \mathrm{~h}$ in an oven. The exposure time in the flame was $30 \mathrm{~s}$ according UL-94-2001 [34]. Two markings were made in the direction of the longitunidal axis, at $(25 \pm 1) \mathrm{mm}$ and $(100 \pm 1) \mathrm{mm}$, which determined the useful area to be tested. The foam was placed on a device and firing begins. The time necessary to burn the useful area or the occurrence of flame extinction was measured. The burning rate or flame speed was determined in $\mathrm{mm} / \mathrm{s}$ after triplicate test.

\section{Results And Discussion}

\section{1 Characterization of KL dispersions (KLD)}

The dispersions of $K L$ in MPEG and in a mixture of KL/MPEG with different loading levels of PKO were evaluated for VPF production. Figure $1(a, b, c)$ shows the behavior of $K L$ dispersion as a function of dispersion time, dispersion temperature and ratios of KL/MPEG. In order to obtain more accurate results of dispersibility of $\mathrm{KL}$ in MPEG, filtration was used for agglomerates solid separation. The dispersion degree of KL in the MPEG at different ratios (10/90, 20/80 and 30/70) increased dramatically with time and temperature increases. These results show that the temperature and dispersion time has a directly effect on the dispersion degree of KL. In the optical microscopic images of KL/MPEG dispersion (Fig $2 \mathrm{a}, \mathrm{b})$, which contained brown $\mathrm{KL}$ particles with size less than $70 \mu \mathrm{m}$ and low degree of dispersion at $75^{\circ} \mathrm{C}$ and $2.5 \mathrm{~h}$ compared at $75^{\circ} \mathrm{C}$ and $4.5 \mathrm{~h}$ (Fig $2 \mathrm{~b}$ ). However, the dispersion of KL/MPEG with different ratios of KL/MPEG (10:90, 20:80 and 30/70 w/w), conducted at $75^{\circ} \mathrm{C}$ and $4.5 \mathrm{~h}$ showed high degree of dispersion (Fig 2c). Optical microscopic image with polarized light (Fig 2b) showed KL particles with size less than $60 \mu \mathrm{m}$. KL dispersions were also evaluated using a Zehntner- Grindometer (Fig. S1 in the Supplementary Information) and particles with size between 40-60 $\mu \mathrm{m}$ were observed. Data showed that the $\mathrm{KL}$ dispersion using a constant $30: 70 \mathrm{w} / \mathrm{w}$ ratio of MPEG/PKO at $90^{\circ} \mathrm{C}$ increased with the PKO contents (Fig. 3), showed good dispersion with little brown microparticles. The degree of dispersion and viscosity of $\mathrm{KL}$ dispersion in the MPEG/PKO mixtures at $90^{\circ} \mathrm{C}$ were significantly affected by the PKO 
contents. It is observed that at $90^{\circ} \mathrm{C} \mathrm{KL}$ has a very high dispersibility (up to $91 \%$ ), which illustrated that the dramatic increase in the dispersion of $\mathrm{KL}$ in the presence of MPEG/PKO mixture, providing a better dispersion of smaller microparticles compared to the KL/MPEG dispersion at same dispersion time (3.5h). This suggests that the degree of dispersion of KL in MPEG/PKO mixtures is affected at the loading levels of PKO, time dispersion temperature, but this does not suggest that $\mathrm{KL}$ is completely soluble.

The viscosity of the KL dispersions decreased with the addition of PKO (Fig. 3). The dispersion of KL has directly affected the viscosity of KL/MPEG/PKO dispersions. The incorporation of KL into petroleumbased polyols would be expected to be difficult given that $\mathrm{KL}$ is highly polar, while polyols are of relatively low polarity. This could be attributed to the good dispersion of $\mathrm{KL}$ in the presence of PKO, polarity and better interaction between KL/MPEG/PKO mixtures. Normally, the viscosity of the KL dispersions in polyols depends on the polyol viscosity, hydroxyl groups, molar mass and chemical reaction with lignin $[10,19,23]$. Ahvazi et al. [23] suggested the formation of ligno-polyol through both physical and chemical linkages between lignin hydroxyl groups with polyester polyol. According to Hayati et al. [19], the differences in particles size, quantity and dissolution of $\mathrm{KL}$ in polyols has a directly effect on the viscosity and stability of polyol/lignin dispersions. Pan and Saddler [38] have shown that the addition of KL to polyether triol (Voranol ${ }^{\circledR} 270$ ) dramatically increased the viscosity only above a $30 \mathrm{wt} \%$ loading. Haridevan et al. [20] have shown that the viscosity of the polyols increased with $\mathrm{KL}$ loading levels and $\mathrm{KL}$ particles with size less than $2.4 \mu \mathrm{m}$ was observed. In summary, the MPEG/PKO mixtures was a promising dispersant for KL and VPF production. The effects of the PKO without chemical modification with PEG on the $\mathrm{KL}$ dispersion and particle size were necessary for further investigation and VPF production.

\subsection{Foam properties}

VPFs were synthesized with different contents of KL (0-3.9 pphp) and PKO (0 -15 pphp). Table 2 summarizes the observed properties of all VPF formulations, as identified in Table 1. The formulations P1 was stablished as the baseline to help elucidate the trends of the system as $\mathrm{KL}$ and PKO were added. The differences in degree of dispersion, content of KL/PKO have affected the degree of cross-link with $\mathrm{NCO}$ groups, the gel time and density. For instance, the addition of $\mathrm{KL}$ increased the gel time from $57 \mathrm{~s}$ (P1) to $115 \mathrm{~s}$ (F4 and F6) and apparent density of foams from $38.6 \mathrm{Kg} / \mathrm{m}^{3}(\mathrm{P} 1)$ to $81.8 \mathrm{Kg} / \mathrm{m}^{3}$ (P4). The gel time increased as the content of $\mathrm{KL}$ increased in the $\mathrm{KL} / \mathrm{PKO}$ mixtures and the content of PKO and MPEG increased in the VPF formulation, especially for P4 and P6 (Table 2). The incorporation of KL decreases the growth speed from $3.9 \mathrm{~mm} / \mathrm{s}$ (P1) to $2.0 \mathrm{~mm} / \mathrm{s}$ (P5). In contrast, the gel time decreased and the growth speed increased when MPEG was changed by PKO in VPF formulation (P7). The apparent density of all foams obtained with KL/PKO mixtures was slightly higher than the reference foam sample (P1). However, the KL content in the formulation had a greater effect than PKO to increase the apparent density of the VPFs, when comparing to the P1 and P7 foams (Table 2). The KL may act as barrier to reactions of polyols with isocyanate, since the hindered hydroxyls from $\mathrm{KL}$ are much less reactive than those from the polyols [10]. At the same time, $\mathrm{KL}$ at different degrees of dispersion/miscibility can induce distinctly different effects on the microstructure and properties of foams [20]. The self-association of the 
$\mathrm{KL}$ with polyol and poor degree of dispersion limits access to hydroxyl groups to reactions with isocyanate. Similar results were reported by Pawlik and Prociak [25] for PU foams using bio-polyol based on palm oil. Wang et al. [39] described that when KL was used to produce PU foams, the apparent density was higher than the density of PU foams produced with KL modified with PEG2000, suggesting that the modification of $\mathrm{KL}$ was beneficial to produce PU foams.

Comparing P4 and P6 formulations, it is possible to observe that the shrinkage values are related to the reaction temperature and micro particles agglomerates, that affect the cellular morphology of the foam. Higher shrinkage values were obtained for $3.9 \mathrm{pphp}$ of $\mathrm{KL}$. The results showed that replacing the petroleum-based polyol (MPEG) with the KL decreased the foaming reactivity. VPFs prepared by directly replacing MPEG 550 with KL presented higher gel time, higher densities, and lower growth speed. In the case of foam produced without KL (P1) and MPEG (P7) there was a relevant difference in the properties (Table 2). The temperature profile of VE-PU with KL was prominently different from the control foam (P1) and the time to obtain maximum temperature showed relevant differences regardless of the amount of $\mathrm{KL}$. The maximum reaction temperature value of VPFs (P2-P7) was lower than the temperature obtained for P1 (Table 2). When KL was used, less reaction temperatures were obtained, which can lead to inadequate curing of the PU foams and open cells. The reaction temperature depends on accessibility of hydroxyl groups in $\mathrm{KL}$, especially aromatic hydroxyl groups [10]. It was found that significant changes in the foam formulation would be required to obtain VPF foams with higher content of KL/PKO.

Table 2 Properties of VPFs obtained with different KL/MPEG/PKO contents.

\begin{tabular}{|llllllll|}
\hline Properties & Runs & & & & & & \\
\cline { 2 - 8 } & $\boldsymbol{P 1}$ & $\boldsymbol{P 2}$ & $\boldsymbol{P 3}$ & $\boldsymbol{P 4}$ & $\boldsymbol{P 5}$ & $\boldsymbol{P 6}$ & $\boldsymbol{P 7}$ \\
\hline Gel time (s) & 57 & 111 & 102 & 115 & 97 & 115 & 68 \\
\hline Growth speed (mm/s) & 3.9 & 1.8 & 1.8 & 1.3 & 2.0 & 1.2 & 3.0 \\
\hline Shrinkage $(\%)$ & 5.4 & 4.9 & 9.8 & 21.5 & 4.3 & 19.2 & 3.5 \\
\hline $\begin{array}{l}\text { Density }\left(\mathrm{kg} / \mathrm{m}^{3}\right) \\
\text { Average cell size }(\mathrm{mm})\end{array}$ & 38.6 & 46.5 & 53.3 & 81.8 & 45.5 & 79.9 & 42.1 \\
\hline $\begin{array}{l}\text { Maximum reaction temperature } \\
\left({ }^{\circ} \mathrm{C}\right)\end{array}$ & $97.8 \pm 1.1$ & $6.4 \pm 1.9$ & $6.0 \pm 1.4$ & 6.2 & 5.1 & $3.8 \pm 1.8$ & 5.5 \\
\hline $\begin{array}{l}\text { Viscosity of KL dispersions at } \\
40^{\circ} \mathrm{C} \text { (mPa.s) }\end{array}$ & 40.0 & 200.0 & 60.0 & 300.0 & 60.0 & 120.0 & 20.0 \\
\hline
\end{tabular}

Fig. 4 and 5 shows the photograph and SEM images of the cross-section of the VPFs with different $\mathrm{KL} / \mathrm{MPEG} / \mathrm{PKO}$ contents. The addition of KL affects the cell morphology, cell size and color. One can clearly see the change in coloration from white (P1) to dark brown with the addition of KL. The images P2, P3, P4 and P6 (Fig 4a and 5a) revealed different shades of brown proportional to its content in 
formulation, light for P2 and darker towards P4 and P6. The VPFs (P1, P5 and P7) showed no relevant differences in color, with a light yellow/white coloration (Fig 4a and 5a). The average cell size of the foams increased, and shapeless cells were obtained as the content of KL increased (Fig. $4 b$ and $5 b$ ). Interestingly, the reduction of MPEG 550 affects the viscoelastic properties and more opened cells were obtained due to the different microstructure, hydroxyl number and low reactivity of KL with $\mathrm{pMDI} /$ polyols In addition, the inclusion of $\mathrm{KL}$ could lead to the formation of urea linkages, which could contribute to obtaining shapeless and opened cells. This behavior may be attributed to the presence of smaller cells that increase apparent density when $\mathrm{KL}$ was used, acting as nucleating agent and resulting in a lower free volume. Wang et al. [39] described that when modified lignin was used to produce PU foams, thicker cells were obtained for higher content of the modified lignin. With these results, we could conclude that $\mathrm{KL}$ increases density, affects the morphology and consequently other foam properties, even so, it is worth saying that the amount of each polyol varies between F4 and F6 and could have an effect on properties.

Regarding the VPFs produced without KL (P1 and P7) and with 1.3 pphp of KL (P5), more regular and homogeneous cells was obtained than the samples produced with $\mathrm{KL}$ up to 1.3 pphp. SEM images show visually that the cell size of the foams with $3.9 \mathrm{pphp}$ of $\mathrm{KL}$ increased than the control foam (Table 2) and more regular cells were obtained with low $K L$ contents (Fig. $5 b$ ), especially to P5 (1.3 pphp of KL and 15 pphp of PKO). As observed in previous sections, three factors (particle size of dispersing KL, PKO content, and the viscosity of the mixture) have affected the cellular structure morphology and the stability of the foams. Comparing SEM micrographs of the foams (P1, P2 and P7) with the same polyol polyether composition (PEO/PO), the KL affected the morphology of the foams more when compared to the P2 foam obtained with $1.9 \mathrm{pphp}$ of KL. Pawlik and Prociak [25] described favorable effects (regular cell structure and closed cell content) of palm oil polyol in flexible PU foams, due to the emulsifying action of PKO. Therefore, despite the use of KL/PKO mixtures to produce VPFs, the standard formulation must be adjusted up to a certain $\mathrm{KL}$ concentration in order to obtain VE-PU foams with properties similar to those of the control foam sample (P1). Among the proportions of KL/MPEG/PKO studied, the formulation P5 presented the most promising results for VPF application.

\subsection{Mechanical properties of VPFs}

\subsubsection{Compression set}

The compression set values of all VPF samples are summarized in Fig $6 \mathrm{a}$ and expressed the recovery ability of the foams after permanent compression at $70^{\circ} \mathrm{C}$ for $22 \mathrm{~h}$ and $50 \%$ of thickness. Figure $6 \mathrm{a}$ shows that the compression set $\left(50 \%\right.$ for $22 \mathrm{~h}$ at $70^{\circ} \mathrm{C}$ ) for VPF samples with KL/MPEG/PKO foams (P2P6) are about 6.5 times less than VPF reference (P1). Therefore, the addition of KL/PKO mixture decreases the compression set values in comparison to the control foam value (P1). Low compression set values is a good indicator of higher elasticity and durability of VPF. In addition, a large number of aromatic structures led to the increase of the hard segments in the foam [39]. According to Thring et al. [43] at higher unmodified lignin (30 wt \% or above), hard and brittle foams were obtained with decreased compression strength. Regarding the VPF produced without KL and MPEG (P7), compression set values 
decreased in comparison to the control foam value (P1). The use of KL increases the thickness of the cells, observed by the reduction of cell size, and the reaction between hard and flexible segments. The compressive properties of PU foams depend considerably on their densities, crosslinking density and cellular structure morphology. According to Hayati et al. [19], enhanced miscibility of lignin in polyol would lead to a greater cross-link density and improved the compressive strength (by $4 \%$ ) of the foams compared to the control without lignin. These results are comparable with resilience, tear strength and density results (Fig $6 a, b)$, which showed that the increases are due to the increase in crosslink density of polyurethanes.

The resilience of VPF samples with different contents of KL/MPEG/PKO mixtures increased significantly with the increasing contents of KL (F2-F4) and PKO (F5-F7) in comparison to the control (P1) (Fig 6a). The resilience values increased from 3.0 to $28 \%$ with increasing content of KL/PKO mixture. The resiliency in both samples increase with increasing apparent density. For P4 sample, the resilience was higher than that for P1 and relevant differences, regardless of the content of PKO were observed on the resilience values for P4 and P6. Increasing content of PKO from 5 pphp to $15 \mathrm{pphp}$, decreased the resilience. In addition, more resilient foams recovered in less time [13], which for VE foam applications is considered satisfactory. The resilience is extremely important in the case of VPF for some industrial applications due to its longer delay in strain response after having undergone a stress stimulus. According to Pawlik and Prociak [25], the resilience of modified foams increased with increasing content of palm oil polyol due to the higher closed cell content in the foam. However, the resilience and final height were affected by the morphology of the foams and thickness of the cells, specifically by the ratio between soft and hard segments.

Fig. $6 \mathrm{~b}$ shows the tear strength value of VPF samples with different contents of KL/MPEG/PKO mixture. The results showed that replacing the petroleum-based polyol (MPEG) with the KL/PKO mixtures increased the tear strength. In the case of P7 sample, a greater tear resistance was obtained ( 277 $\mathrm{N} / \mathrm{mm}$ ) compared to the control sample (P1, 38 N/mm). High tear strength (Fig $6 \mathrm{~b})$ and low compression set values (Fig 6a) are a good indicator of higher elasticity and durability of VPF samples. The results in Fig. $6 \mathrm{~b}$ indicate that the tear strength is dependent on the amount of $\mathrm{KL} / \mathrm{PKO}$ mixture, $\mathrm{KL}$ content and density of VPF. Density plays a significant role in the mechanical properties of VPF samples. Increasing the density results in higher resilience and elongation at rupture as well as greater tear strength. The tear strength of P4 and P6 samples with KL/PKO (3.9 pphp of KL) are on average 35\% greater than their VPF sample (P1 reference). This behavior may be attributed to the presence of smaller cells that increase apparent density when $\mathrm{KL}$ was used, resulting in a lower free volume. Thus, density and tear strength have similar behavior, except for P7 sample obtained without MPEG and KL.

The recovery time behavior curves of $P U$ foams indicate that the recovery time could be dependent on the amount of KL/MPEG/PKO mixture, PPG diol content and morphology of the cells. The reduction of PPG diol (foam P6) and the introduction of $3.9 \mathrm{pphp}$ of $\mathrm{KL}$, decreased the final height of the foam P6 and no recovery was observed for foam P4, in comparison to the control foam (P1) (Fig 7). The recovery time and final height of the foams P2, P3 and P7 showed no relevant differences regardless of the contents of 
$\mathrm{KL}, \mathrm{MPEG}$ and PKO used in comparison to the reference (P1). However, the resilience and final height were affected by the morphology of foam, cross-link reaction, KL content and thickness of the cells, specifically by the ratio between soft and hard segments $[11,25,28]$. The results from the foam obtained through P6 presented lower final height (Fig 7) and higher Tg (Fig 8b) and this may be related to the greater density and $K L$ content, revealing a certain morphological instability of P6. To the sample P4, also with 3.9 pphp of $\mathrm{KL}$, no recovery time was obtained and can be explained by the high shrinkage values (Table 2). The samples P4 and P6 produced with 3.9 pphp of KL display higher shrinkage, approximately 4.0 and 3.5 times more in shrinkage values, when compared to P1 foam. These results showed a direct relationship between the recovery time and the shrinkage values of the foams.

\subsubsection{Dynamic mechanical analysis (DMA)}

DMA has been used as a sensitive technique to measure the glass transition temperature $(\mathrm{Tg})$ and storage modulus of the VPFs containing different amounts of KL/MPEG/PKO mixtures (Fig. 8a,b). The storage and loss modulus were measured as a function of increasing temperature, and the $\mathrm{Tg}$ was determined. In the case of VPF obtained without KL and PKO (P1) the Tg was lower than the VPF samples with KL/PKO mixtures. It is clearly that the increase of PKO in VPF formulation gives more regular cell structure. The $\mathrm{Tg}$ of the foams obtained with KL/PKO mixture increased from 17 (P1) to $40^{\circ} \mathrm{C}$ (P6) with increasing content of PKO. The storage modulus and tan $\delta$ curves are dependent on the contents of $\mathrm{KL}$ and PKO in the PU formulation and on the distribution of hard and soft segments. Favorable effects of the PKO were also observed in the Tg of VPF samples, especially for P4 and P6 samples (Fig.8b). The presence of PKO acts as an additional surfactant [25] and dispersing agent for KL in the PU formulation [28]. The ratio of soft and hard segments, their distribution and separation in the PU matrix significantly affects viscoelastic properties of VPF and the tan $d$ values. According to Haridevan et al. [20] slight increase in Tg was observed with incorporation of KL. The differences in degree of dispersity of $\mathrm{KL}$ and cell size have affected the cross-link reaction with MDI as observed by the $\mathrm{Tg}$ values. Increasing hard segment content result in foams more viscous with increasing hard segment contents [44]. In the case of foams obtained without KL and MPEG (P7), the Tg increased from $\sim 17^{\circ} \mathrm{C}$ (reference) to $38^{\circ} \mathrm{C}$. Therefore, replacing MPEG 550 with PKO affects not only the $\mathrm{Tg}$, but also the hard and soft segment domains in the polymer matrix as well as the viscoelastic properties of the foams. Ahvazi et al. [23] described that the isocyanate functional group would act as a cross-linking, connecting the $K L$ and polyol. In fact, the efficiency of the MPEG acting as a plasticizer can be evaluated by its impact on the $\mathrm{Tg}$ of the foams. Yoshida et al. [40] described that the low $\mathrm{NCO} / \mathrm{OH}$ ratio and lignin content $<20 \mathrm{wt} \%$ usually resulted in the PU foam being rather soft and flexible, while hard and tough PU foams were often obtained at a rather high lignin content or high $\mathrm{NCO} / \mathrm{OH}$ ratio. However, the replacement of the MPEG with $\mathrm{KL}$ and PKO mixtures in VPF formulations increased the Tg value from $17{ }^{\circ} \mathrm{C}(\mathrm{P} 1)$ to $40^{\circ} \mathrm{C}(\mathrm{P} 4)$. It is possible to observe, by the DMA analysis (Fig. $8 \mathrm{~b}$ ), that the $\mathrm{Tg}$ of the samples are greater dependent of the PKO content in the formulation.

\subsubsection{TGA and flammability analysis}

Page $13 / 22$ 
The thermal degradation behavior and flammability of VPFs with different contents of KL/MPEG/PKO are shown in Fig 9a,b. TGA analysis were performed under nitrogen atmosphere and the data from the thermal curves appear in Table 3. The thermal stability of the produced foams showed no relevant differences regardless of the contents of KL/MPEG/PKO used in comparison to the reference (P1). Decomposition of the foams was observed in two main steps over a broad temperature range of $230-700^{\circ} \mathrm{C}(\mathrm{Fig} 9 \mathrm{a}, \mathrm{b})$. The temperatures were defined as $\mathrm{Td}_{\text {onset, }} \mathrm{Td}_{\text {endset }}$ and $\mathrm{T}_{\max }$ (temperature corresponding to the highest weight loss). Significant decomposition of VPF samples occurred between $220-450^{\circ} \mathrm{C}$. The $\mathrm{Td}_{\text {onset }}$ was observed between $220-250^{\circ} \mathrm{C}$, which was probably due to the decomposition of low small molar mass species, urethane bonds $[20,25,41,42]$. At $\approx 420{ }^{\circ} \mathrm{C}$, decomposition can be considered as being completed and this event corresponds to the major weight loss when compared to the other events $\left(T_{\text {max }}\right)$. This step is associated with thermal degradation of the soft segments, urethane linkages, polyols and KL [41,42]. As reported in the literature, the three degradation steps of the PU foam are related to the presence of soft and hard segments, internal crosslinking, physical properties and also foam structure [25]. A similar behavior was observed by Pawlik and Prociak [25] for PU foam produced with palm-oil based polyol. After $430^{\circ} \mathrm{C}$ slow weight loss was observed, and is related to other remaining structures formed, such as diisocyanate, internal crosslinking and lignin aromatic rings [41]. The thermal stability of PU generally increases with the increasing intermolecular attraction forces, rigidity of the structure, cross-linking density and presence of thermostable linkages. According to Bernardini et al. [42], the degradation of KL occurs in two phases, at $285^{\circ} \mathrm{C}$ and $410^{\circ} \mathrm{C}$, therefore, as the study mentioned, since the lignin content in the different formulations is less than $10 \mathrm{wt} \%$ by weight, its loss of mass cannot be easily distinguished in the TGA trends. Septevani et al. [45] related that the thermal properties and dimensional stability of PU foam produced by substituting petroleum-polyether polyols with PKO-based polyester polyol were only comparable to the control PU foam produced with petroleum-polyether polyols at a loading of up to 20 $w t \%$ in the polyol mixture.

The residual mass at $800{ }^{\circ} \mathrm{C}$ for the foams was similar and between 8.0 to $10.5 \%$ (Table 3). Therefore, the addition of KL/PKO mixture did not significantly affect the thermal degradation behavior and stability of PU foams. The residual mass of the produced foams showed no relevant differences regardless of the contents of KL/MPEG/PKO used in comparison to the control (P1). On the other hand, the flammability decreased with addition of the KL and PKO. According to Haridevan et al. [20] reported an increase of thermal stability, residual mass and flame retardance performance with an increase of $K L$ content.

The flammability behavior of the obtained VPFs were evaluated by means of horizontal burning tests. For further comparison of the burning behavior of VPFs, the average burning times were calculated and presented in the Fig. 9b. The burning time of produced foams reduced with the replacing content of MPEG and with the decreasing addition of the KL. The control sample (P1) exhibits inferior result with average burning rate of $1.4 \mathrm{~mm} / \mathrm{s}$ as compared to the sample $P 5$. The studies showed that the addition of $\mathrm{KL}$ and PKO did not improve significantly the burning rate of foam samples compared to the control foam without KL and PKO. The residual mass presented in Table 3 of the samples is a substantial 
parameter for evaluating the degree of combustion under nitrogen atmosphere. However, based on residual mass and flammability results, one can suggest that there are no relevant differences regardless of the contents of KL/PKO used in comparison to the control (P1). Finally, in terms of fire resistance, the standard formulation used in this work must be adjusted with the addition of fire retardants to meet various standards used in the industry.

Table 3. TGA data obtained from the thermal curves.

\begin{tabular}{lccccc} 
Properties & \multicolumn{5}{c}{ VPFs } \\
\cline { 2 - 6 } & $\boldsymbol{P 1}$ & $\boldsymbol{P 3}$ & $\boldsymbol{P 4}$ & $\boldsymbol{P 5}$ & $\boldsymbol{P 7}$ \\
\hline $\mathrm{Td}_{\text {onset }}\left({ }^{\circ} \mathrm{C}\right)$ & 250 & 239 & 220 & 244 & 250 \\
\hline $\mathrm{Td}_{\text {max }}\left({ }^{\circ} \mathrm{C}\right)$ & 414 & 417 & 412 & 418 & 422 \\
\hline $\mathrm{T}_{\text {endset }}\left({ }^{\circ} \mathrm{C}\right)$ & 520 & 534 & 512 & 518 & 545 \\
\hline Residual mass $(\%)$ & 9.0 & 10.4 & 10.5 & 8.0 & 8.70 \\
\hline
\end{tabular}

The maximum decomposition temperature $\left(T_{\max }\right)$ was obtained from the peaks in DTG curves.

\section{Conclusion}

In this work, the effect of the different contents of the KL/MPEG/PKO mixture for replacement of petroleum-based polyol on the foaming and final properties of VPF foams was successfully evaluated. It is possible to produce VPFs by replacing petroleum-based polyol (MPEG 550). KL lignin was dispersed into a MPEG/PKO mixture by simple physical mixing at 75 and $90^{\circ} \mathrm{C}$ for $4.5 \mathrm{~h}$. The viscosity of the $\mathrm{KL}$ dispersions decreased with the addition of PKO. The dispersion of KL in a MPEG/PKO mixtures at $90^{\circ} \mathrm{C}$ increased from $91 \mathrm{wt} \%$ to $98 \mathrm{wt} \%$ with increasing content of PKO. The standard formulation used in this work must be adjusted up to a certain KL concentration in order to obtain VE-PU foams with properties similar to those of the control foam sample. The use of $\mathrm{KL}$ affects foam mixture processability and final properties of VE-PU foams (ie. growth profile, density, reaction temperature, cell morphology and shrinkage). The reduction of maximum reaction temperature in the synthesis of VE-PU foams, led to densification and a higher degree of shrinkage, especially for foams obtained with $3.9 \mathrm{pphp}$ of KL. The recovery time and final height of the foams $\mathrm{P} 2, \mathrm{P} 3$ and $\mathrm{P} 7$ showed no relevant differences regardless of the contents of KL, MPEG and PKO. Replacing the MPEG with the KL/PKO mixtures increased the tear strength and decreased the compression set $\left(50 \%\right.$ for $22 \mathrm{~h}$ at $\left.70^{\circ} \mathrm{C}\right)$. VPF samples with KL/PKO mixture exhibited a $35 \%$ increase in tear strength and 6.5 times less in compression set values than the reference (P1). Thermal properties of VE-PU foams showed no relevant differences regardless of the contents of KL and PKO used. The results indicated that the highest affinity between polyols polyether and KL did not necessarily result in obtaining the most homogeneous VPFs. The $\mathrm{Tg}$ and resilience of the foams obtained increased with increasing content of KL/PKO mixture. In addition, the results obtained in this work 
created new approaches for the production of VPFs and should allow these materials to have a wide range of applications, as well as in packaging and in mattresses. Further studies involving the mixture of $\mathrm{KL} / \mathrm{PKO}$ to replace polyol polyether are in progress and could attract high interest for industrial applications.

\section{Declarations}

\section{Acknowledgements}

The authors gratefully acknowledge the financial support of the São Paulo Research Foundation (FAPESP, Brazil, grant 2018/12469-7), National Council for Scientific and Technological Development (CNPq, Brazil, grant 314898/2018-2). We also thank The Dow Company Brazil for technical support and for the reagents used in this work.

\section{Conflicts of interest}

The authors declare that there is no conflict of interest regarding the present study.

\section{Sample credit author statements}

All authors contributed to the study conception and design. Material preparation, investigation, data collection and analysis were performed by Camila Campos Flôres, Lara Robert Nahra, Isabelle C.Z. Rodrigues, Thiago C Rufino and Mauricio Pinheiro Oliveira. The first draft of the manuscript was written by Camila Campos Flôres, Maurício Pinheiro Oliveira and all authors commented on previous versions of the manuscript. All authors read and approved the final manuscript.

\section{References}

1. Duval A, Lawoko M React Funct Polym (2014) 85:78-96.

2. Gandini AL, Lacerda TM (2014) Prog Polym Sci 48:1-39.

3. Messmer NR, Guerrini LM, Oliveira MP (2018) Polym Adv Techn 29:1094-1106.

4. Zhang Q, Zhang G, Xu J, Gao C, Wu Y (2015) Rev Adv Mater Sci 40:146-154.

5. Crestini C, Crucianelli M, Orlandi M, Saladino R (2010) Catalysis Today 156:8-22

6. Tomani P, Axegard P, Berglin N, Lovell A, Nordgre D (2011) Cellul Chem Techn 45:533-540

7. Kienberger M, Maitz S, Pichler T, Demmelmayer P (2021) Processes 9:804. https://doi.org/10.3390/pr9050804

8. Garlapati VK, Chandel, AK, Kumar SPJ, Sharma S, Sevda S, Ingle AP, Pant D (2020) Renewable Sustainable Energy Rev. 130, 109977. 
9. Phanopoulos C, Pans G, Teboul M, Lima Garcia J (2017) Incorporation of lignin in polyurethane products. EP $3365382 \mathrm{~B} 1$.

10. Alinejad M, Henry C, Nikafshar S, Gondaliya A, Bagheri S, Chen N, Singh SK, Hodge DB, Nejad M Polymers (2019) 11:1202. https://doi:10.3390/polym11071202

11. Yang L, Wang X, Cui Y, Tian Y, Chen H, Wang Z (2014). Polym Adv Techn 25, 1089-1098. https://doi:10.1002/pat.3356

12. Cassales A, Ramos LA, Frollini E (2020) Int J Biol Macromol 145:28-41.

13. Cinelli P, Anguilesi I, Lazzeri A (2013) Eur Polym J 49:1174-1184

14. Ma X, Chen J, Zhu J, Yan N (2021) Macromol Rapid Commun 42:2000492.

15. Lang JM, Shrestha UM, Dadmun M (2018) The Effect of Plant Source on the Properties of LigninBased Polyurethanes. Front Energy Res. https://doi.org/10.3389/fenrg.2018.00004

16. Li HQ, Shao Q, Luo H, Xu J (2016) J Appl Polym Sci 133

17. Badri KH, Ahmad SH, Zakaria S (2001) J Appl Polym Sci 81:384-389

18. Lat DC, Bagus I, Jais IBM, Mohammed K, Baharom B, Samat N, Zainuddin AN (2016) Mal J Fund Appl Sci 12:126-129

19. Hayati AN, Evans DAC, Laycock B, Martin DJ, Annamalai PK (2018) Ind. Crops Prod. 117, 149-158.

20. Haridevan H, McLaggan MS, Evans DAC, Martin DJ, Seaby T, Zhang Z, Annamalai PK (2021) ACS Appl Polym Mater 3:3528-3537

21. Paberza A, Cabulis U, Arshanitsa A (2014) Polimery 59:477-481. https://doi: 10.14314/polimery.2014.477

22. Shaari NZK, Lye OT, Ahmad S (2004) J Oil Palm Res 16:66-71

23. Ahvazi B, Wojciechowicz O, Xu P, Ngo TD, Hawari J BioResources (2017) 12:6629-6655.

24. Septevani AA, Evans DAC, Chaleat C, Martin DJ, Annamalai PK (2015) Ind Crops Prod 66:16-26

25. Pawlik H, Prociak A (2012) J Polym Environ 20:438-445

26. Jaratrotkamjorn R, Tanrattanakul V (2020) J Appl Polym Sci Bio-based flexible polyurethane foam synthesized from palm oil and natural rubber. https://doi.org/10.1002/app.49310

27. Sonnenschein MF (2015) Polyurethane Science, Technology, Markets and Trends John. Wiley \& Sons, New York

28. Flôres CC, Rufino TC, Oliveira MP (2021) J Polym Res 28:481. https://doi.org/10.1007/s10965-02102827-0

29. Nahra LR, Cerqueira MR, Oliveira MP, Guerrini LM (2020) J Polym Res 27:1-14

30. American Society for Testing and Materials - ASTM D-2849-69 (1980) Methods of Testing Urethane Foam Polyol Raw Materials. 913-931, Philadelphia, PA.

31. Brazilian Association of Technical Standard test method - ABNT NBR-8537, (2003) Flexible polyurethane foam - Density determination, Rio de Janeiro 
32. Brazilian Association of Technical Standard test method - ABNT NBR 9429 (2016) Flexible polyurethane foam - Dimensions determination, Rio de Janeiro

33. Raimbault C, Laure P, François G, Boyer S, Vincent M, Choquart F, Agassant J (2021) Polym Eng Sci 61:1243-1256

34. Standard for Safety of Flammability of Plastic Materials for Parts in Devices an Appliances - UL-94, version 6, march 28, (2013)

35. Brazilian Association of Technical Standard test method - ABNT NBR-8797 (2003) Flexible polyurethane foam - Determination of compression set, Rio de Janeiro

36. Brazilian Association of Technical Standard test method - ABNT NBR-8619 (2003), Flexible polyurethane foam - Determination of Resilience, Rio de Janeiro

37. Brazilian Association of Technical Standard test method - ABNT NBR-8516 DE (2015), Flexible polyurethane foam - Determination of tear strength, Rio de Janeiro

38. Pan X, Saddler JN (2013) Biotechnol Biofuels 6:12

39. Wang S, Liu W, Yang D, Qiu X (2019) Ind Eng Chem Res 58:496-504

40. Yoshida H, Mörck R, Kringstad KP, Hatakeyama H (1987) J Appl Polym Sci 34:1187-1198

41. Luo S, Gao L, Guo W (2020) J Wood Sci. 66: 23. https://doi.org/10.1186/s10086-020-01872-5

42. Bernardini J, Cinelli P, Anguillesi I, Coltelli MB, Lazzeri A (2015) Eur Polym J 64:147-156

43. Thring RW, Vanderlaan MN, Griffin SL (1997) Biomass and Bioenergy 13:125-132

44. Jeong H, Park J, Kim S, Lee J, Ahn N (2013) Fibers Polym 14:1301-131

45. Septevani AA, Evans DAC, Chaleat C, Martin DJ, Annamalai PK (2015) Ind. Crops Prod 66:16-26

\section{Figures}

(a)

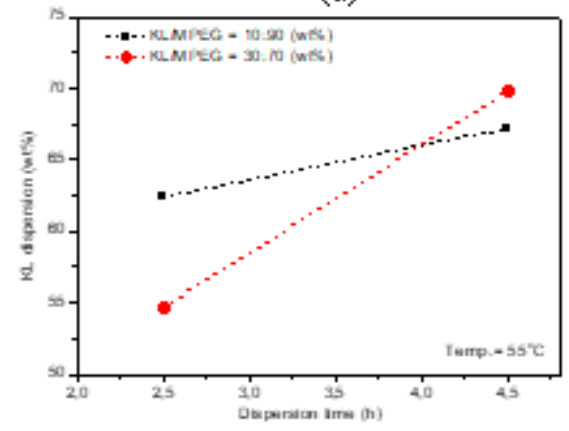

(b)

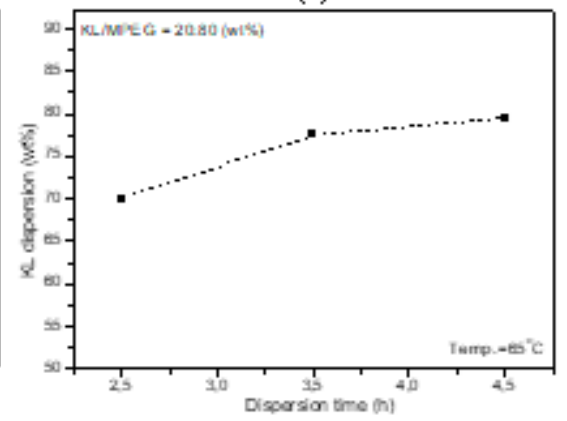

(c)

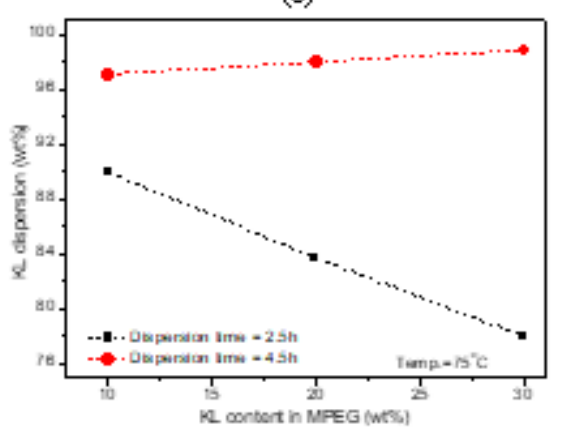

\section{Figure 1}

Dispersion of KL in the MPEG at different ratios of KL/MPEG (10:90, 20:80 and 30:70 w/w) as a function of dispersion time $(\mathbf{a}, \mathbf{b})$ and $\mathrm{KL}$ content in MPEG (c). 


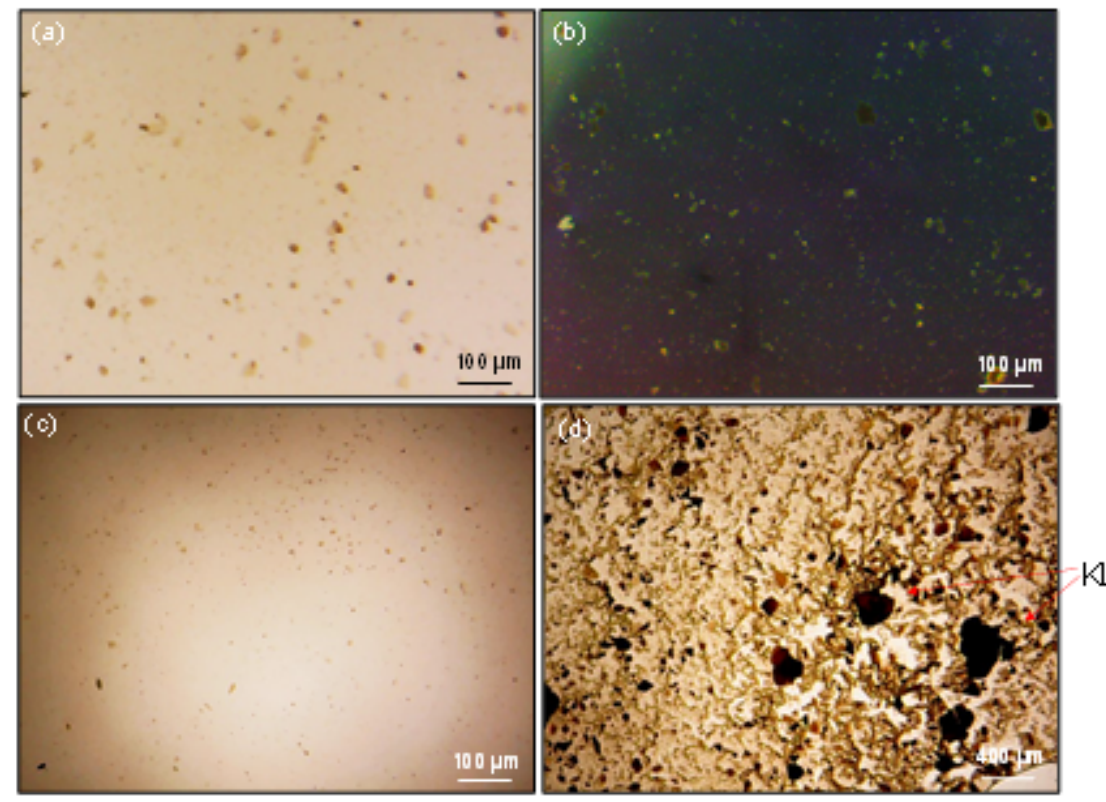

Figure 2

Optical microscopy images of KL/MPEG dispersion with 30:70 w/w ratio of KL/MPEG and dispersion time of $3.5 \mathrm{~h}$ at $75^{\circ} \mathrm{C}$. $(\mathbf{a}, \mathbf{c}, \mathbf{d})$ without and $(\mathbf{b})$ with polarized-light.

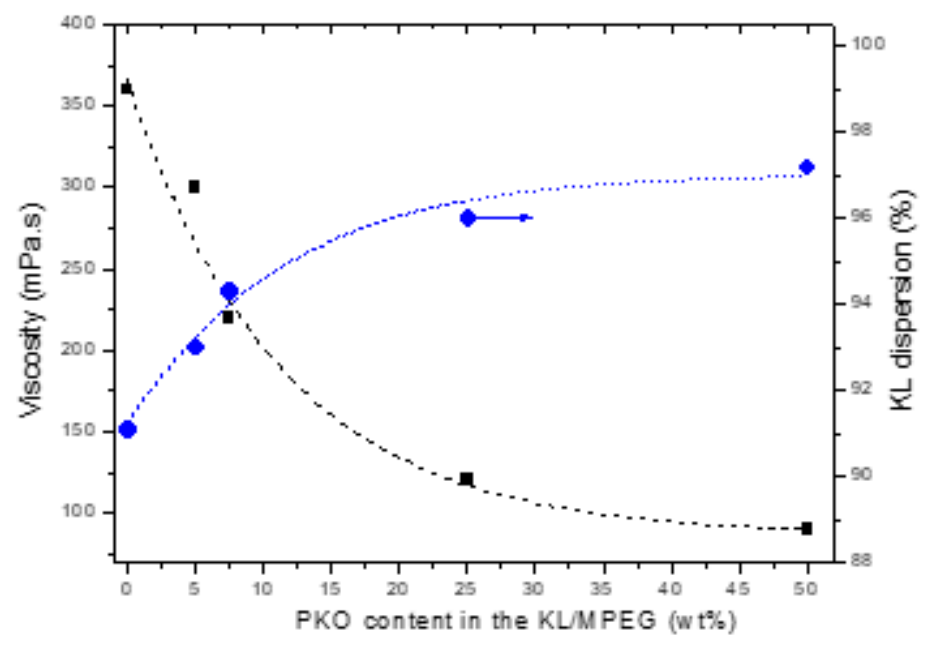

\section{Figure 3}

Viscosity and dispersion degree of $\mathrm{KL}$ in KL/MPEG with different contents of PKO measured at $40{ }^{\circ} \mathrm{C}$. $\left(\mathrm{KL} / \mathrm{PEG}=30: 70 \mathrm{w} / \mathrm{w}\right.$, dispersion temperature $=90^{\circ} \mathrm{C}$ and time $\left.=3.5 \mathrm{~h}\right)$ 
P1

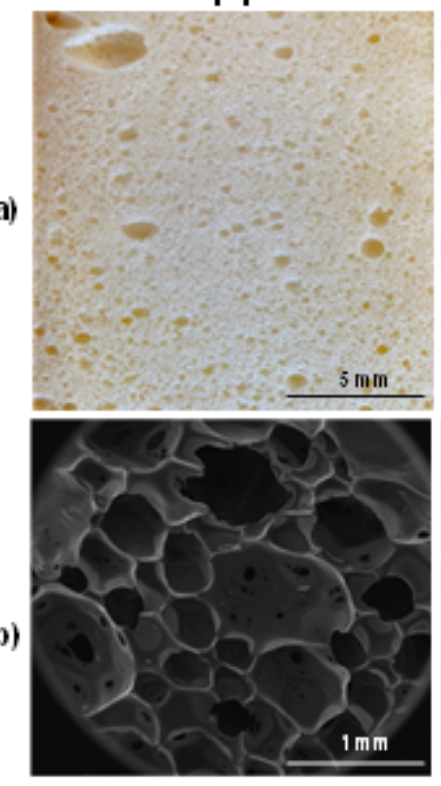

P2

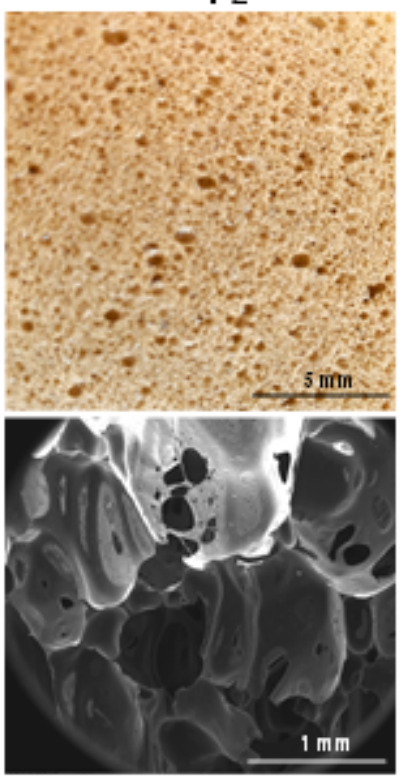

P3

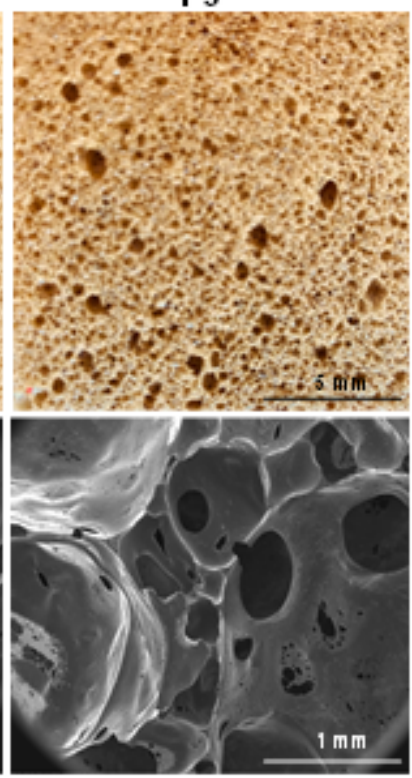

Figure 4

Photographs (a), and SEM images (b), of VPFs with different KL/MPEG/PKO contents. (P1) 0/15/0 pphp, (P2) 1.9/5.6/7.5 pphp and (P3) 2.6/7.4/10 pphp.

(a)

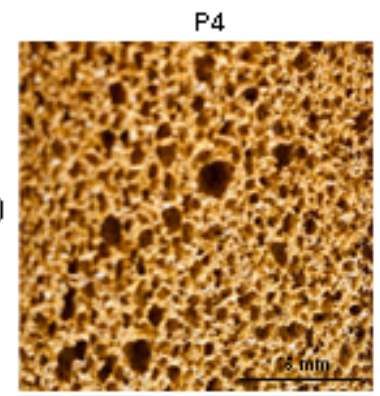

P5

P6
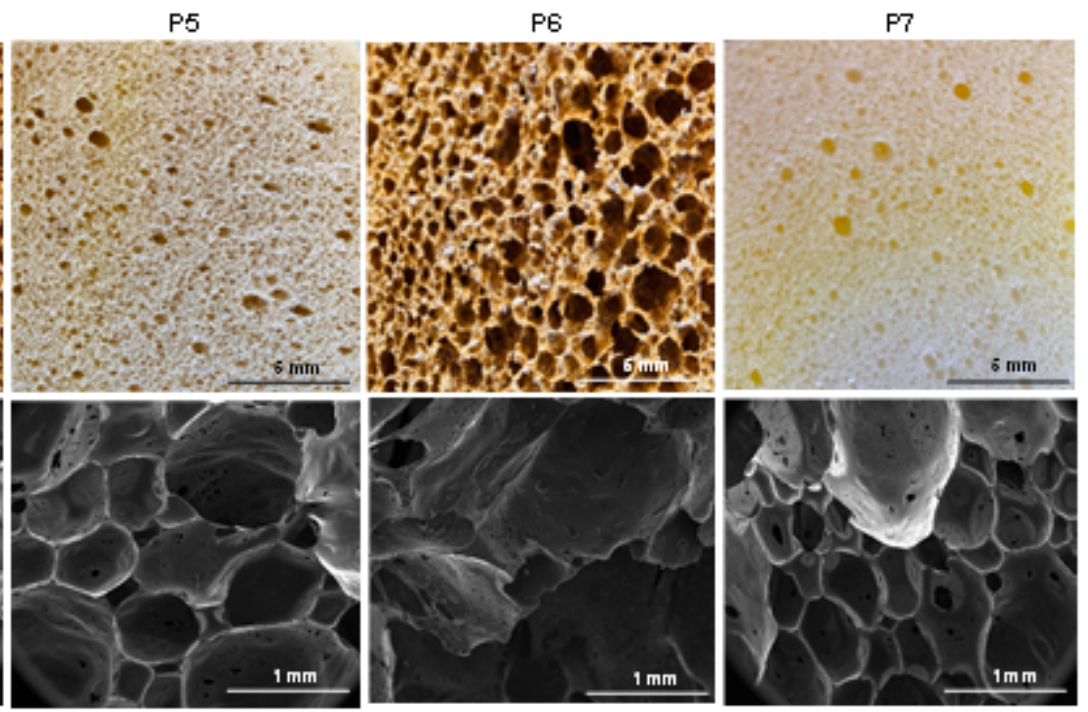

Figure 5

Photographs (a), and SEM images (b), of VPFs with different KL/MPEG/PKO contents.

(P4) 3.9/11.1/5 pphp, (P5) 1.3/3.7/15 pphp, (P6) 3.9/11.1/15pphp and (P7) 0/15 pphp. 
(a)

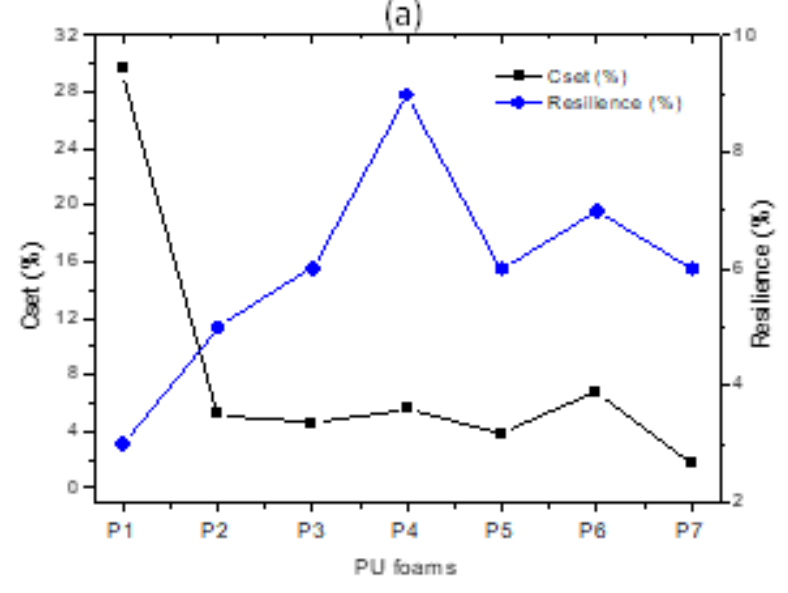

(b)

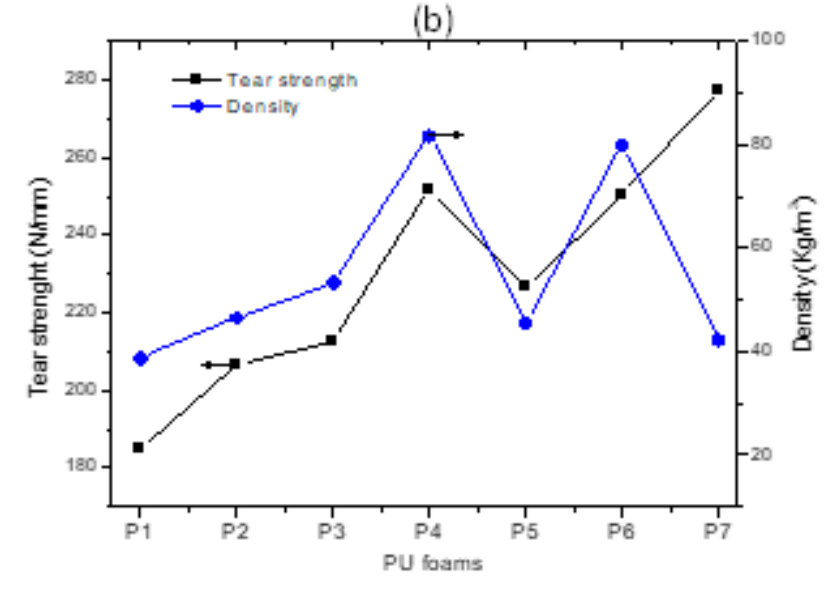

Figure 6

Compression set at $50 \%$, resilience, tear strength and density of VPF samples with different contents of $\mathrm{KL} / \mathrm{MPEG} / \mathrm{PKO}$ and PKO mixture. (a) compression set and resilience; (b) tear strength and density.

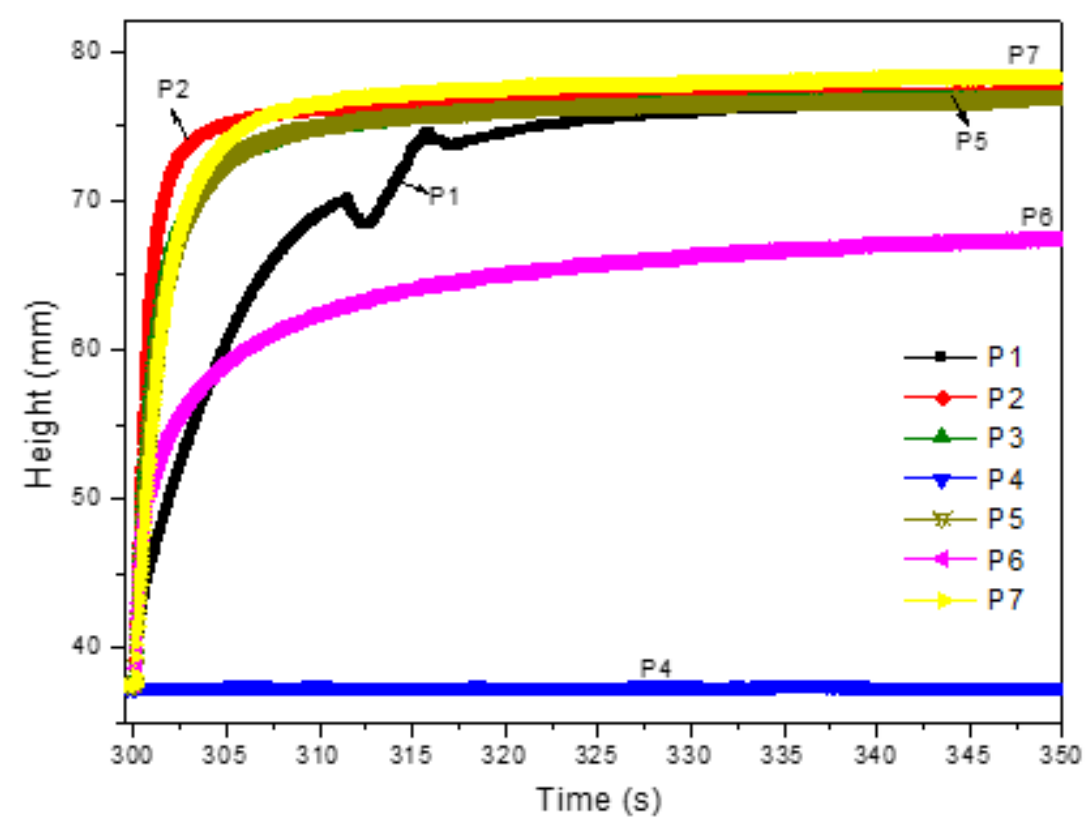

Figure 7

Recovery time of VPF samples with different contents of KL/MPEG/PKO. 

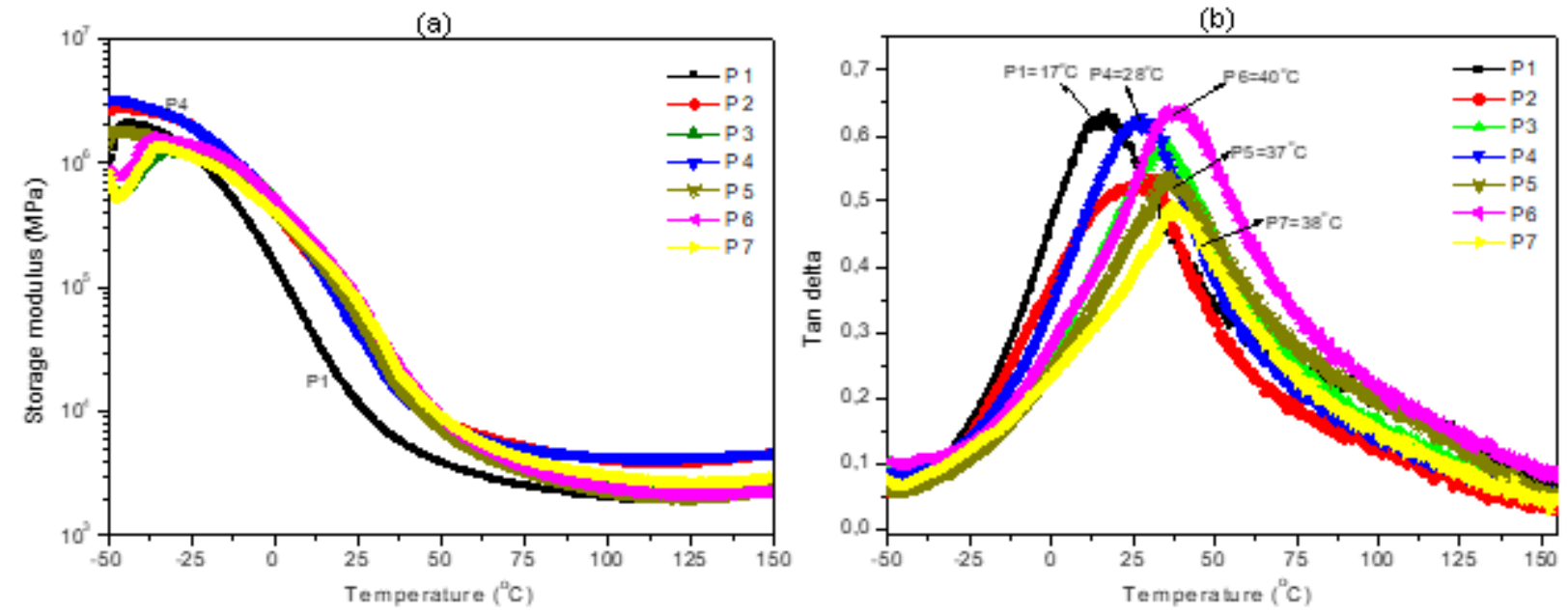

Figure 8

DMA analyses of VPFs with KL/MPEG/PKO mixtures (P1-P7). (a) storage modulus and (b) tan delta.

(a)

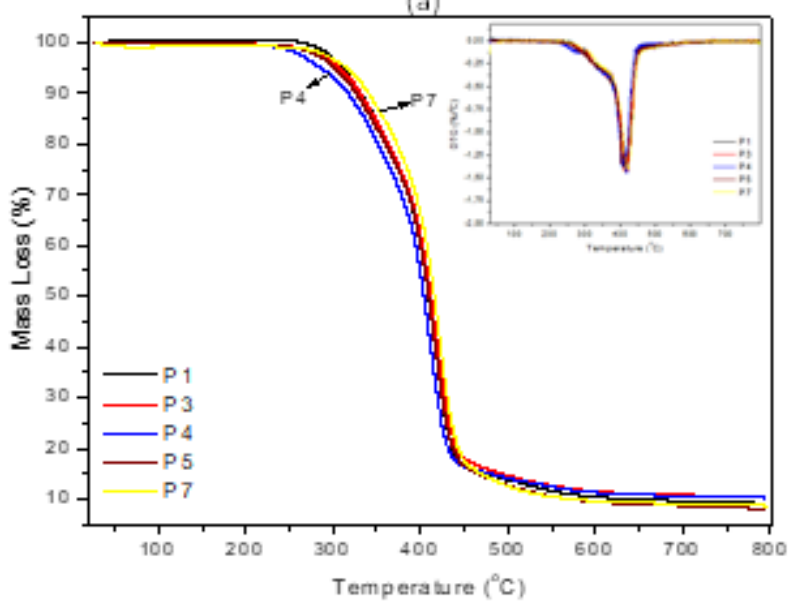

(b)

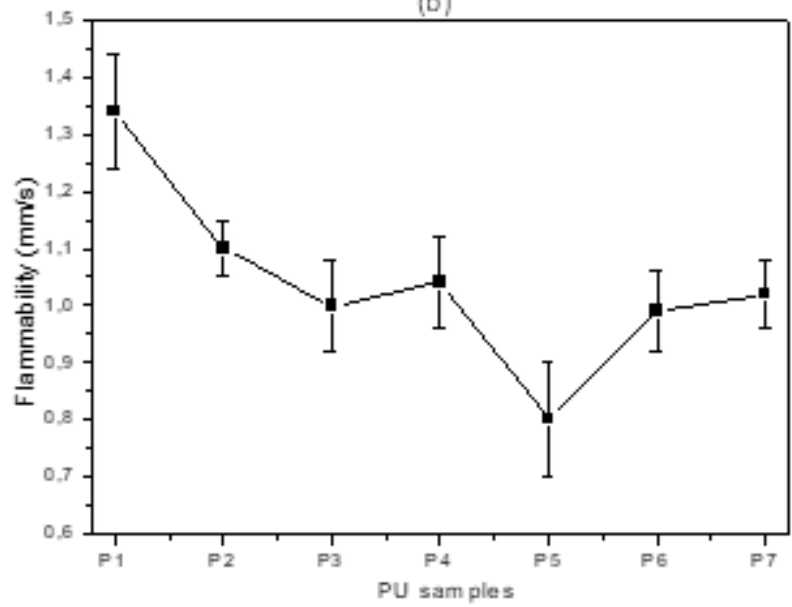

Figure 9

TGA curves (a) and flame retardance (b) of VPFs produced with different contents of KL/MPEG/PKO.

\section{Supplementary Files}

This is a list of supplementary files associated with this preprint. Click to download.

- Supplementarylnformation.docx 